\title{
UN POLO «PERVERSO» DEL LENGUAJE VAGO: EL ENMASCARAMIENTO EN EL DISCURSO POLÍTICO
}

\section{A "PERVERSE" SIDE OF VAGUE LANGUAGE: MASKING IN POLITICAL DISCOURSE}

\section{Luis Cortés Rodríguez}

Universidad de Almeria/CySOC

Resumen

El lenguaje vago se caracteriza por su polaridad, que va de una función "positiva», relacionada con la cortesía, la espontaneidad y la fluidez expresiva (especialmente en la conversación), a otra "perversa», con la que se pretende enmascarar datos precisos, ciertas realidades que en un determinado momento conviene mitigar o encubrir. En este artículo, nos vamos a ocupar de ambas funciones, si bien nos centraremos en esta segunda, la negativa: una maniobra más entre las múltiples acciones manipuladoras que se pueden llevar a cabo a partir de los mecanismos lingüísticos. Para ejemplificar el resultado de tal función, nos valdremos de uno de sus campos de acción preferido: el discurso político.

Palabras Clave: discurso oral, lenguaje vago, lenguaje político, mecanismos discursivos
Abstract

Vague language is characterized by its polarity, which ranges from a "positive" function connected with politeness, spontaneity and expressive fluency (especially in conversation) to a "perverse" one, aimed at masking specific data or circumstances that should be mitigated or hidden. This paper deals with these two functions, albeit with special focus on the latter, a negative procedure out of the many manipulation strategies that can be deployed using linguistic devices. The result of this function will be exemplified in the light of evidence from the field of political discourse.

KEY WORDS: oral discourse, vague language, political language, discursive devices 


\section{INTRODUCCIÓN}

El concepto de vaguedad aplicado al lenguaje hemos de asociarlo a la Filosofía; aquí surge la aportación de Peirce (1902: 748), para quien una proposición es vaga si presenta elementos e interpretaciones acerca de los cuales es imposible saber si, de haber sido contemplados de manera más limitada por el hablante, este los habría considerado como negativos o positivos para la propuesta. Más próxima a lo que hoy entendemos por lenguaje vago fue la definición de Alston (1964), otro filósofo del lenguaje, al indicar que un término será vago si no expresa una solución tan definida o tan clara como cupiera pensar que lo hubiera sido con la aplicación del término adecuado. Esto implica, por ejemplo, que la locución adverbial alrededor de, usada en cualquier contexto, siempre será un marcador de vaguedad. Parecida idea fue defendida por Channell (1994). Distinta, sin embargo, fue la opinión de Zhang (1998); el autor, que parte del estudio de Kempson (1977: 124-128), diferencia entre cuatro conceptos: borrosidad o falta de claridad, vaguedad, generalización y ambigüedad. La idea más aceptada de vaguedad cabe asociarla, en especial, con lo que Zhang denomina fuzziness (difuso, borroso); de hecho, para caracterizar este término recurre a un ejemplo como «María le pidió a Juan que comprara unas 20 cervezas y unas pocas manzanas»; con ese mismo criterio, de un partido de fútbol podríamos opinar que no ha estado mal y de un cuadro que es bastante original; un montón de libros ¿pueden ser treinta, cuarenta? y muchos amigos, ¿cuántos son?1

Cutting (2015) indicó tres funciones del lenguaje vago: textual, epistémica y social. La función textual es de tipo léxico y cohesión gramatical; cita ejemplos como «Esta es la escuela en la que trabajo. Me encanta el lugar», en el que el nombre general «lugar» se refiere anafóricamente a «la escuela»; otro caso citado es «Voy a hacer la sopa con patatas, col y demás», en el que el significado del marcador de cierre dependerá de que el destinatario conozca los otros productos que contiene la categoría «y demás»; la segunda función, la epistémica, se puede ver en aquellos términos que quitan especificidad o muestran duda sobre lo dicho; por ejemplo, o algo así; la función sociopragmática se ocupa, en general, de la cohesión social, de las estrategias de cortesía y de crear una amistosa atmósfera, contribuyendo a la naturalidad, la informalidad y la convergencia de la charla cotidiana.

Pensamos que el principio de adecuación, existente en cualquier hablante, suele acoplar la cantidad y la calidad de la información a los propósitos advertidos en la interacción, y de ahí que las citadas expresiones vagas se puedan utilizar con total confianza donde juzgue el hablante que no se requiere una mayor precisión. Por ello, entre los estudiosos, existe una acepción general y amplia del término, la cual habla de vaguedad tanto en aquellas ocasiones en que su empleo resulte favorable y oportuno para la fluidez y espontaneidad conversacional como en esas otras en que se manifieste desfavorable e inoportunamente; esto último aparecerá cuando la situación rechace el uso de esos términos vagos y requiera otros que delimiten más la proposición, que transmitan una información más

\footnotetext{
${ }^{1}$ El segundo término, generality, para Zhang abarca las expresiones que no especifican los detalles, lo que dificulta la comprensión; así, el significado de ciudad es general porque no especifica si una ciudad es grande o pequeña, moderna o antigua; igualmente ocurre con vecino; ¿es mayor, joven, austriaco, vive a cincuenta metros o encima de mi casa? También se dará en enunciados como "María cambió al bebé», donde no se sabrá si el bebé es su bebé, el bebé de su vecina o el hijo de su nuevo compañero.
} 
concreta; es tal hecho, por ejemplo, lo que cabe pensar que ocurra con frecuencia en un discurso político. Son estos casos, que estarían dentro de la variedad epistémica de Cutting (2015), los que ocuparán nuestra atención.

Para la expresión del lenguaje vago, en general, se han separado dos tipos de mecanismos: las formas vagas y los modificadores vagos. El primer grupo lo forman palabras y expresiones que son vagas en sí mismas, es decir, elementos léxicos y estructuras gramaticales inherentemente vagas: de sustantivos vacíos, asunto, cosa, a verbos como hacer o marcadores de cierre: y eso, y tal, y todo eso, etc. Los modificadores vagos son expresiones que añaden vaguedad a otros elementos, estructuras o enunciados normales: de cuantificadores vagos, poco, mucho, bastantes, algunas, a marcadores interpersonales con una función modalizadora²: posiblemente, quizás, tal vez, etc.

\section{El LENGUAJE VAGO Y SU POLO POSITIVO}

Cada día más, los investigadores descubren nuevas funciones del lenguaje vago, la mayoría de ellas positivas. Y es que ciertas palabras o estructuras poco precisas no solo muestran, en ocasiones, alguna duda sobre lo que se dice, sino que también, en otras, sirven para suplir el desconocimiento de algo; en dichos casos, su empleo evita romper la fluidez de la conversación, incluso harán, según otros, que la relación con el interlocutor sea menos formal y más amistosa. Cumplen, por tanto, una función positiva. Un autor como Peires (1997) ha insistido en la importancia del lenguaje vago para la expresión de la cortesía; es más, considera que es la principal causa de que los hablantes de segundas lenguas empleen tal lenguaje vago, algo que también había defendido la aludida Channell (1994: 190). Ambas opiniones son ciertas, pues parece claro que cuando un anfitrión le dice a su invitado si quiere vino, cerveza o alguna otra bebida está intentando abrir posibilidades de elección y, en consecuencia, está siendo cortés; se está valiendo del lenguaje vago en su función de cortesía y no de ocultamiento (perversión); consecuentemente, es en esta acepción en la que hemos de entender aquellas opiniones que han considerado que las mujeres al emplear tradicionalmente más modalizadores corteses, dada su actitud conciliadora y su mayor consideración (Cameron 1996, Tannen 1986, 1990, 1993), han hecho un uso mayor de palabras vagas.

A veces, no es la cortesía, pero sí la posibilidad de auspiciar la fluidez conversacional e incluso de facilitar la comunicación la que lleva a un uso que se considera también positivo del lenguaje vago. Imaginemos a un señor que al llegar a la confitería le pide a la empleada que le ponga para llevar a casa «dos de esos y dos de aquellos»; es evidente que tal empleo vago viene motivado por no saber o no recordar que esos son piononos y aquellos se llaman milhojas. Hemos puesto ejemplos de registro coloquial para estas funciones positivas, registro donde lo normal no es la precisión, sino la espontaneidad. Esta manifestación de la vaguedad es especialmente empleada en las conversaciones, donde los interlocutores «are generally satisfied with vague expressions, such as vague amounts and propositions of persons, ideas, and objects, because they fit in with the purposes of

\footnotetext{
${ }^{2}$ Es evidente que habrá que distinguir de algún modo la modalización simple y aquella que entrañe no tanto el interés por modalizar una expresión cuanto por ocultar intencionadamente un contenido.
} 
interaction which are primarily interactional rather than transactional» (Brown and Yule 1983: 14).

Por todo ello, también, cada día son más los estudiosos que reclaman la necesidad del acercamiento a estas formas y mecanismos, especialmente en la enseñanza de segundas lenguas, algo en lo que ha insistido recientemente Alkhatnai (2017). Ya, Grasso (2014) reconoció que, contrariamente a lo que han afirmado algunos autores, los fragmentos que incluyen lenguaje vago no necesariamente carecen de información, sino que proporcionan una información distinta a fragmentos similares con lenguaje más preciso:

\begin{abstract}
El lenguaje vago tiene una función informativa, cuyo aspecto varía, según la forma en la que se materializa: en algunos casos provoca matices en la información dada; propone planos que ayudan al oyente a individualizar entidades discursivas en el grado que sea necesario para los propósitos comunicativos y guía al receptor hacia la parte más importante del mensaje. En otras ocasiones, informa acerca del grado de incertidumbre del hablante en relación con lo expresado. También provee información sobre la identidad generacional de quien lo usa, generando en muchas oportunidades formas económicas y eficientes de transmitir una idea (Graso, pág. 42)
\end{abstract}

\title{
3 El LENGUAJE VAGO Y SU POLO NEGATIVO. EL DISCURSO POLÍTICO
}

\subsection{La vaguedad como una forma más de enmascaramiento}

El enmascaramiento lingüístico es un mecanismo de manipulación. Manipular, dice el DRAE en su acepción tercera, es «Intervenir con medios hábiles y, a veces, arteros, en la política, en el mercado, en la información, etc. con distorsión de la verdad o la justicia, y al servicio de intereses particulares». Esta definición, de la que posiblemente podamos prescindir del «a veces», implica una actuación interesada que encontraremos en los más diferentes campos de acción: del publicitario, donde localizamos constantemente pseudotecnicismos a modo de las divinas palabras valleinclanescas, al periodístico, cuando en nuestra televisión española, tras conocerse que España encabeza junto a Grecia la lista de países con más desempleo, se decide que en vez de dar esta información era mejor contar que «España lidera el descenso del desempleo en Europa en febrero»; el motivo del «júbilo» en la cadena estatal se apoyaba en que en nuestro país había bajado el aludido desempleo dos décimas -como en Malta y Polonia- en tanto la media de la UE era de una décima.

Cualquier análisis discursivo debe ser multidimensional, lo que no excluye que el lingüista establezca categorías para términos que puedan cumplir, y de hecho cumplen, funciones diversas con rasgos comunes. El enmascaramiento lingüístico, a través de determinados mecanismos equívocos o de acciones tendenciosas y equívocas, puede fomentar un uso partidista del lenguaje, puede evitar aquello que se debería decir pero que no se desea hacer o, por ejemplo, puede crear ambigüedad o redundancia en lo dicho con el objetivo de conseguir la ocultación perseguida; en última instancia, se trata, en la mayoría de ocasiones, de evadir responsabilidades, bien monologales (en su propia intervención), bien dialogales o reactivas (dando respuestas a medias o no tomando en cuenta aquello por lo que se ha preguntado). Creemos que el enmascaramiento es en alguno de sus aspectos la parte perversa y malintencionada de la modalidad o, al menos, de parte de ella. Tal estrategia del enmascaramiento, decíamos, se puede llevar a cabo tanto mediante mecanismos como mediante acciones. 


\subsubsection{Mecanismos enmascaradores equívocos}

Estamos ante actuaciones lingüísticas cuya selección enunciativa (léxica o proposicional) lleva consigo que lo dicho pueda ser entendido o interpretado con sentidos distintos o que dé ocasión a juicios diversos según quienes lo escuchen; sus manifestaciones más importantes se dan en forma de cuatro tipos de lenguaje, que denominamos partidista, redundante, vago y ambiguo ${ }^{3}$. Así, con respecto al primero, el discurso político está lleno de términos y frases que continuamente adquieren un significado nuevo con una intención manipuladora; cuando el Gobierno español inventa la expresión "saneamiento del sector bancario" estaba manipulando, pues con tal sintagma se intentaba ocultar a los ciudadanos un vocablo proscrito en aquel momento: rescate; años después, en 2017, así no solo lo reconoció el entonces ministro de Economía Luis de Guindos, si no que defendía la necesaria aplicación de tal rescate ${ }^{4}$.

En otra ocasión, el mecanismo equívoco puede recurrir a la redundancia discursiva, aquella que se usa a lo largo de un fragmento utilizando demasiadas palabras para expresar pocos conceptos; da la sensación con su empleo de que el político está más pendiente de adornar lo que dice o de dejar que pase el tiempo del que dispone que del asunto del que realmente se está ocupando.

Puede ocurrir, también, que el orador de turno no recurra al lenguaje partidista ni al redundante, pero sí a la ambigüedad, y lo hará a través del juego de palabras, de la búsqueda intencionada de un léxico con doble significado, etc. Con motivo del intento de separación de Cataluña, en sesión celebrada el diez de octubre de 2017 en el Parlament catalán, no solamente la mayoría de mecanismos y acciones a los que nos referimos en este artículo se manifestaron durante todo el desarrollo del discurso retorcido y enmascarador de president Puigdemont, sino que tuvo un final ${ }^{5}$ digno de tal ejercicio de manipulación y un referente ya cuando se habla del lenguaje que se puede entender de varios modos o que puede admitir distintas interpretaciones:

1. Llegados a este momento histórico, y como presidente de la Generalitat, asumo, al presentarles los resultados del referéndum ante todos ustedes y ante nuestros conciudadanos, el mandato de que el pueblo de Catalunya se convierta en un Estado independiente en forma de república. Esto es lo que hoy hacemos con toda solemnidad, por responsabilidad y por respeto. Y con la misma solemnidad, el Govern y yo mismo proponemos que el Parlament suspenda los efectos de la declaración de independencia para que en las próximas semanas emprendamos un diálogo sin el cual no es posible llegar a una solución acordada.

Tan rebuscada ambigüedad llevó a millones de españoles a no saber, días después, si cabía hablar de un nuevo Estado, aunque con sus efectos suspendidos, o si solo había

\footnotetext{
${ }^{3}$ López Martínez (2003); Márquez (2012), García Platero y Castillo (2013), Hernández y Gómez (2014), Córdoba (2015); Crespo-Fernández (2016), Barranco (2017), etc.

${ }^{4}$ El 20/06/2017, el diario El Mundo publicaba la noticia de que el ministro de Economía, Luis de Guindos, había defendido que el rescate al sector bancario para el que, según Banco de España, fueron necesarios más de 60.000 millones de ayudas públicas y privadas fue totalmente necesario; en dicha información se resaltaban estas palabras del ministro: "Si no hubiese habido rescate bancario, la recesión en España habría sido el doble, y si no hubiese habido rescate bancario, España habría salido del euro".

${ }^{5}$ Lo que ofrecemos es la traducción del texto del catalán al español, tal y como lo han publicado varios diarios tanto catalanes como españoles.
} 
asumido, sin ejecutar, el mandato (¿?) de que Cataluña se convirtiera en un Estado independiente, lo que llevaría a pensar en una inexistente, y así parece que fue, declaración de independencia. $Y$ es que una enunciación como la buscada por los autores del texto supone un caso de suprema ambigüedad, de deformación retórica, pero de esa Retórica que Platón definía como una práctica inmoral y perversa en el terreno político. A estos mecanismos citados en el parágrafo anterior, habrá que sumar lo que denominaremos acciones enmascaradoras.

\subsubsection{Acciones enmascaradoras}

Las acciones enmascaradoras pueden ser de dos tipos: evasivas y tendenciosas. Las primeras, ubicadas preferentemente en la parte reactiva del interlocutor, han sido estudiadas en políticos ingleses, norteamericanos y, más recientemente, asiáticos; según tales análisis6, los citados políticos se han valido de treinta acciones distintas para manifestar la evasión; entre ellas, fueron frecuentes: a) respuestas que ideaban cuestiones distintas a las planteadas por el interlocutor; en estos casos, solían refugiarse una y otra vez en el ideario de su partido o en algo relacionado y dicho previamente, b) respuestas parciales, c) respuestas equívocas, d) respuestas que cuestionan a su vez la pregunta recibida, etc. Si al político se le interroga sobre un tema complejo y se ve obligado a responder brevemente, tiene que elegir entre dos opciones poco atractivas, alternativas: reducir el problema a una simple respuesta incompleta o emplear largas y tortuosas evasivas. Es más, cuando se le inquiere sobre un tema en particular, puede tener una información confidencial o no tener información alguna; en el primer caso, tendrá que optar entre revelar lo sabido o encubrirlo, incluso negarlo; en el segundo, habrá de tomar la incómoda elección entre reconocer su ignorancia o improvisar, inclusive inventar, su respuesta. Un ejemplo que al menos los españoles recordarán de acción enmascaradora evasiva, entre otras muchas que se producen constantemente, la tuvimos en la respuesta del presidente de la Generalitat, Carles Puigdemont, quien ante una pregunta7 de las denominadas por la gramática académica total polar indirecta, cuya respuesta solo puede ser sí o no, contestó con una larga carta en la que no estaban ni ese sí ni ese no.

Las acciones enmascaradoras tendenciosas son, sin duda, las más estudiadas, incluso abundan los trabajos aplicados a líderes hispanoamericanos y españoles ${ }^{8}$; son acercamientos en que se pretende analizar cuestiones como los argumentos falsos, los razonamientos laxos o incluso la invención de causas de imposible demostración. Un caso, por ejemplo, de este tipo -y volvemos al tema político más traumático de estos últimos años: el del intento de separación de Cataluña- lo pudimos ver en televisión (septiembre de 2017) cuando una periodista (en un programa emitido en la cadena La Sexta) preguntaba al vicepresidente de la Generalitat, entonces, Oriol Junqueras, sobre la independencia y este respondía una y otra vez que ellos, los políticos catalanes en el poder,

\footnotetext{
${ }^{6}$ Nos referimos a trabajos como los de Bull y Mayer (1993), Bavelas y otros (1990), Cutting (2007), Lin (2013), Feldman, Kinoshita y Bull $(2015,2017)$, Choi, Bull y Reed (2016) o Feldman (1916).

${ }^{7}$ Recordemos que el Gobierno acordó requerirle lo siguiente: «que confirme si alguna autoridad de la Generalidad de Cataluña ha declarado la independencia de Cataluña»; para solicitar a continuación «su respuesta afirmativa o negativa», por si cupiera alguna duda gramatical al respecto.

${ }^{8}$ Erlich y Caimi (2007), Sánchez García (2010), Gutiérrez Morales (2012), Bolívar (2014), Méndez (2014), Piquer y Vellón (2014), Nicasio (2017), etc.
} 
cumplían lo que dice el derecho internacional: el reconocimiento de la autodeterminación de los pueblos. Este falso argumento, repetido una y otra vez durante la entrevista, implicaba un enmascaramiento tendencioso de la realidad, pues tal reconocimiento, según la mayoría de juristas, solo se puede aplicar en determinados casos, ninguno de los cuales se daba en Cataluña. El político estaba basando su defensa a partir de una causa falsa. Otro ejemplo, por seguir con el caso catalán, lo tenemos en el entonces conseller de Asuntos Exteriores, Relaciones Institucionales y Transparencia, Raül Romeva, quien, preguntado en una televisión extranjera sobre el motivo de la salida de mucha empresas de Cataluña, declaró que estas se van horrorizadas por el comportamiento de la policía española, el día uno de octubre de 2017, en el intento de referéndum; el juicio no podía ser menos analítico, porque ¿qué empresario había dicho eso?, ¿en qué se basaba para dicha opinión?

Podemos, por tanto, establecer determinados grupos de mecanismos y acciones que conducen al enmascaramiento lingüístico; pueden ser estos:

1. Mecanismos enmascaradores equívocos

a) Lenguaje partidista (atenuado y peyorativo)

b) Lenguaje vago

c) Lenguaje redundante

d) Lenguaje ambiguo

2. Acciones enmascaradoras

2.1. Acciones evasivas

a) Dar respuestas directas aproximadas

b) Dar medias respuestas

c) Cuestionar las preguntas para no responder

d) etc.

2.2. Acciones tendenciosas

a) Presentar juicios sin análisis.

b) Juntar razonamientos sólidos con razonamientos laxos

c) Inventar causas falsas

d) etc.

En consecuencia, para nosotros, el lenguaje vago, en su polo perverso, es una manifestación más del enmascaramiento: concretamente, es uno de sus mecanismos equívocos, junto al lenguaje partidista, redundante y ambiguo.

\subsection{Vaguedad en el discurso político}

3.2.1. Parece evidente que la vaguedad es una manifestación especial de la modalidad, cuyas formas de expresión, además, son las mismas. Esta manifestación del lenguaje vago aporta funciones positivas, como las vistas en el apartado 2, y funciones perversas, que hemos de asociar con el enmascaramiento y que vamos a ejemplificar a través del discurso político; esto no implica, ni mucho menos, que tal función enmascaradora sea exclusiva de 
este, pero sí que en él, que se basa en la confrontación, encuentra un buen hábitat para su acomodo.

Si partimos de Grice (1975), de sus principios de cooperación comunicativa y de sus cuatro máximas para que la conversación se pueda llevar a cabo con éxito, cabe afirmar que un atentado «intencionado» contra alguna de estas máximas ${ }^{9}$ podremos considerarlo en cualquier manifestación lingüística como un acto de perversión; tal acto, en sus diferentes realizaciones, se muestra como una forma de actuación con la que se pretende transmitir una información que, más o menos calculadamente, no es precisa o ajustada a la realidad; la falta de precisión, que acarrea la de información, en muchas ocasiones es interesada y busca la confusión, el partidismo, lo superfluo, etc.

Como ya indicamos en el apartado anterior (3.1), pretendemos introducirnos en los distintos valores de una de esas formas de actuación: la que se transmite a través de la cara perversa del lenguaje vago; su empleo, que lleva consigo el intento de enmascaramiento, dota al término vaguedad de un nuevo sema en su caracterización: la «intencionalidad». Es esta la que marca la diferencia con respecto al resto de funciones del lenguaje vago, pues no podemos olvidar que las formas y modificadores vagos que en determinadas circunstancias servirán para la ocultación de información son los mismos que empleamos en cualquier momento del día para nuestra mayor o menor implicación en lo que decimos o para manifestar un mayor o menor conocimiento de las cosas; así, no será extraño que digamos a nuestro vecino que «La conflictividad en Cataluña es alta a pesar de las conversaciones con el Gobierno de Sánchez». Es indudable que el significado de «la conflictividad es alta» podría ser vago en un contexto determinado dada la existencia del término difuso alta (¿cómo de alta?); sin embargo, en este uso coloquial, como en la mayoría de ocasiones que empleemos la vaguedad, esta cumplirá una función muy distinta a la de la ocultación; será más bien cooperativa porque es posible: a) que no conozcamos con exactitud dicha cifra; b) que pueda resultar dada la situación coloquial irrelevante, o c) que ya se haya aludido anteriormente y no sea necesario insistir en la información para no hacerla excesiva; por tanto, no estamos atentando contra la máxima de calidad, si bien se puede hablar, en un sentido amplio, relacionado con la modalidad, de lenguaje vago. Nuestra acepción, por consiguiente, de la vaguedad elimina, por ejemplo, que podamos asociar lenguaje vago con cortesía, con informalidad o fluidez discursiva.

3.2.2 En 2015, decía Rajoy, siendo consciente de que iba a huir del enmascaramiento y que iba a aportar datos exactos, lo siguiente:

2. Pues bien, señorías, esta es la situación de la economía española a día de hoy. No necesito ya traer promesas ni alentar esperanzas; disponemos de algo mejor: hechos sólidos que se palpan, se miden, y se cuentan porque son realidades objetivas (Rajoy, 2015).

\footnotetext{
${ }^{9}$ Obviamente, nos referimos a la máxima de calidad (seamos veraces de acuerdo con la información que tengamos); máxima de cantidad (informemos sin ser excesivos en dicha información); máxima de pertinencia (que sea oportuno y adecuado lo dicho), y, finalmente, la máxima de manera (procuremos ser claros y breves; evitemos divagaciones innecesarias y procedamos ordenadamente).
} 
Contrariamente, en 2010, Rodríguez Zapatero, presidente del Gobierno de España, en un «Debate en torno al estado de la nación» ${ }^{10}$ (en adelante, DEN), se expresaba de esta otra manera:

3. Para el conjunto de 2011, el Gobierno prevé una contribución neutra de la demanda interna al crecimiento, lo que constituirá una mejora relativa tras la aportación negativa del menos 1,2 por ciento en 2010. Esta mejora se producirá fundamentalmente por la vía de una mayor renta disponible de los hogares debido a la gradual recuperación del empleo y a la moderación de la inflación, que habrán de impulsar, a su vez, una cierta recuperación del consumo [Zapatero 2010].

Si leemos con atención, tendremos la idea de encontrarnos ante un político que tiene que hablar sin ganas de decir; corrían malos tiempos para la presidencia y, lo que es todavía peor, para los españoles en general. ¿Cómo si no hemos de entender sintagmas como «mejora relativa», «una mayor renta» o «una cierta recuperación del consumo?» No parece que el presidente quiera aclarar mucho, porque ¿qué tipo de mejora es una mejora relativa?, ¿cuánto mayor es la renta?, ¿cómo hemos de entender una gradual recuperación, la moderación de la inflación o una cierta recuperación del consumo?

Igualmente cabe pensar de esta otra intervención de Mariano Rajoy, también ese mismo año y en ese mismo DEN:

4. La situación sería muy grave si en el horizonte de los españoles no apareciera más opción que la que usted representa. Afortunadamente saben que cuentan con una alternativa, con otra manera de hacer las cosas, es decir, con una esperanza, que, porque ya lo hizo en su día, sabe lo que hay que hacer y que disfruta del crédito para convocar a toda la nación a la tarea, porque le mueve un propósito obsesivo e indeclinable de crear empleo [Rajoy, 2010].

¿Cuál es la alternativa con la que cuentan?; ¿qué es un diagnóstico objetivo de la situación?; ¿cuál es la otra manera de hacer las cosas?; sin duda, estamos ante una manera vaga e interesada de usar el lenguaje; en este caso, el lenguaje político.

Son dos ejemplos de habla faltos de la determinación de unos límites designativos precisos; son enunciados en los que se intentará decir sin decir, lo que es una manera de manipular al interlocutor. Es la cara «perversa» del lenguaje vago; la misma que encontramos en enunciados como estos:

5. La universidad española cuenta con un gran número de buenos profesores [Aznar, 2001].

6. El señor RAJOY BREY: Señorías, la educación sigue siendo manifiestamente mejorable [Rajoy, 2007].

7. Su capacidad de decisión sobre un número importante de tributos les permite ejercer sus competencias conjugando autonomía y responsabilidad [Aznar, 2002].

8. Este es el camino, señorías, no solo para lograr cuanto antes la recuperación, sino para corregir todos los atrasos relativos que lastran nuestro desarrollo [Rajoy, 2014] ${ }^{11}$.

\footnotetext{
${ }^{10}$ Tales debates han generado siempre un gran interés, pues en ellos Gobierno y oposición abordan los asuntos políticos más importantes del país. Instaurados por Felipe González, en 1983, su celebración es anual, y desde entonces no solamente se han dejado de llevar a cabo en aquellos años en que hay convocatoria de elecciones generales, sino que en 2017 tampoco tuvo lugar por decisión presidencial. El último, por tanto, fue en febrero de 2015.

${ }^{11}$ A partir de este momento, todos los ejemplos pertenecen a Rajoy, y no es porque el presidente popular emplee este tipo de lenguaje en mayor medida que otros políticos, sino porque nos hemos valido de sus discursos en los DEN, en 2013, 2014 y 2015, para la ejemplificación.
} 
El presidente de un Gobierno siempre que pretenda ser contundente podrá disponer de los datos necesarios para aplicarlos en aras de su argumentación, máxime en un DEN; de tales Debates hemos tomado los ejemplos vistos y los que vienen a continuación. Observemos el inicio del discurso de Rajoy en 2013:

9. El señor PRESIDENTE DEL GOBIERNO (Rajoy Brey): Muchas gracias, señor presidente. Señorías, 5.965.400. Esta cifra por sí sola refleja el aspecto más duro y dramático de la situación social y económica por la que atraviesa España. Representa el número de personas, 4.743.000 españoles y 1.222.000 inmigrantes, que cada mañana se enfrentan a la dura realidad del paro. Mas del $26 \%$ de nuestra población activa no encuentra empleo y a más del $50 \%$ de nuestros jóvenes les ocurre lo mismo [...] Señorías, he querido destacar desde el principio este duro aspecto de la realidad para reafirmar el primer y más esencial objetivo que el Gobierno tiene para toda la legislatura: darle la vuelta a esta situación (Rajoy, 2013).

10. Al acercarnos a estos problemas, las preguntas surgen por sí solas: ¿Cómo es posible, señorías, que el número de parados en nuestro país haya crecido en 4.250 .000 personas en poco más de cinco años? ¿Cómo es posible que las cuentas de nuestro sector público, que presentaban un superávit de 2 puntos sobre el PIB, pasaran en solo veinticuatro meses a un déficit del $11 \%$ ? ¿Cómo es posible que la deuda de nuestras administraciones públicas, con la consiguiente carga de intereses, se duplicara en cuatro años? ¿Cómo es posible, señorías, que el déficit de nuestra balanza con el exterior se multiplicara por 4 entre 2003 y 2007 ? ¿Cómo es posible que la recaudación de ingresos del conjunto de las administraciones públicas se redujera en 68.000 millones de euros en dos años? Les aseguro, señorías, que estas preguntas no son un ejercicio retórico, porque de sus respuestas sale una cifra estremecedora: 6.000.000 de parados (Rajoy, 2013).

Extrañamente, en el fragmento siguiente:

11. Nuestras relaciones económicas con el exterior, cuyo mejor indicador es la balanza de pagos por cuenta corriente, van mucho mejor que hace un año, pero no es suficiente. Nuestro sector financiero, tras una profunda reforma, comienza a estar en disposición de cumplir con su función de trasladar el crédito a empresas y familias, pero no es suficiente. El déficit del sector público se reduce e inicia la búsqueda del equilibrio, pero no es suficiente. El clima de opinión sobre nuestra economía mejora ostensiblemente en las instituciones y los mercados internacionales, pero no es suficiente. No es suficiente, señorías (Rajoy, 2013)

el tono del presidente es mucho menos demostrativo y las cifras dan paso a términos sospechosamente vagos: "mucho mejor», "Comienza a estar en disposición», "se reduce e inicia la búsqueda del equilibrio», «mejora ostensiblemente»:

Un tema de tanto interés como el de los logros del Gobierno en este tiempo no parece normal, sin embargo, que se pueda despachar con una serie de vocablos y giros tan poco delimitados como los elegidos; solo unas consultas hubieran permitido saber cuál es el dato de la balanza de pagos, cuál la reducción del déficit del sector público o por qué el clima de opinión sobre nuestra economía mejora ostensiblemente y qué grado de mejora es el de «ostensiblemente». Es posible que no considerara el presidente necesarios los datos apuntados, pues todos ellos tienen solo el objetivo de resaltar, mediante la concessio, el afán del Gobierno por mejorar las cosas; puede ser que ese «mucho mejor» no lo sea tanto o que la «mejora ostensible» no haya alcanzado unos límites tan manifiestos; sea una causa u otra, lo que es palmario es que el mensaje resulta deficiente, escaso, pues quien no da los datos en este tipo de situaciones, los oculta por una u otra causa. Y por eso, pensamos, el lenguaje vago está mostrando su polo negativo, su parte de deformación retórica en el terreno político. 
Recordemos con Alston (1964) que una proposición es vaga si presenta elementos e interpretaciones con los cuales se ofrece una solución no tan definida o clara como cupiera pensar que lo habría sido con la aplicación del vocablo o sintagma adecuados. Es lo que sucede con el adjetivo «moderada», en el ejemplo siguiente:

12. Después de nueve trimestres en recesión, hemos conseguido abandonarla; ya estamos creciendo, aunque sea todavía de manera moderada (Rajoy, 2014).

O con el sentido indeterminado de «una cierta» en este otro caso:

13. Para los que piden una cierta relajación porque el proceso de cambio ya está en marcha, mi respuesta es ni un minuto, ni un solo minuto de relajación o sosiego (Rajoy, 2013).

¿Cuáles son los niveles, cabe preguntarse en el ejemplo que sigue, de esa inferioridad de las empresas españolas con respecto a la de otros países en la financiación no bancaria?; ¿qué otros países desarrollados son esos?:

14. La financiación no bancaria de las pequeñas y medianas empresas está en España en niveles muy inferiores a los de otros países desarrollados (Rajoy, 2013).

No podemos olvidar que estamos analizando textos escritos, detalladamente elaborados por varias personas, para ser oralizados en el Parlamento. Por ello, nos parece claro que cuando un presidente resalta como una conquista de su gobierno la evolución positiva de la balanza de pagos y habla de que «ya ha tenido superávit», la ocultación de la cifra no es casual, sino causal: este superávit es muy reducido, por lo que mejor es su ocultación:

15. A falta de los datos del mes de diciembre, los cinco meses anteriores, de julio a noviembre, la balanza de pagos por cuenta corriente española ya ha tenido superávit (Rajoy, 2013).

¿Cuál es la cifra de la tasa de desempleo, en el ejemplo siguiente?:

16. Sabemos lo que nos falta. La tasa de desempleo está todavía demasiado alta; muchísimos españoles llevan más de un año sin trabajo, y muchísimos más de dos (Rajoy, 2015)

¿Cómo cabe justificar que en un DEN, con tal estado de formalidad, el presidente se limite a señalar que la tasa de desempleo está demasiado alta?; ¿sería muy arriesgado pensar que, tras tres años en el Gobierno, Rajoy quiere omitir esa alta cifra de parados?; el sentido común parece indicarlo así. Asimismo, en 2015, el líder popular parece desconocer las cifras, ni siquiera aproximadas, de la parte de población a la que no alcanza todavía el beneficio de la recuperación económica:

17. Somos también, en lo negativo, un país que arrastra la cifra de una deuda millonaria y de una tasa de paro inaceptable, sin olvidar que a una buena parte de la población no le alcanza todavía el beneficio de la recuperación económica (Rajoy, 2015).

3.2.3 Este lenguaje vago, en algunas otras ocasiones, cumple una función que podemos ubicar entre la perversión y el énfasis; con su empleo, el orador, mediante la falta de concreción, aspira a crear expectativas al auditorio; más adelante, esos términos vagos, una vez cumplidos sus objetivos, son reemplazados por indicadores precisos, delimitados. 
Hay una ocultación positiva de la información, la cual sirve para agrandar el estado de la situación que pretende criticar el orador. Una de las abundantes apariciones la tenemos cuando Rajoy, en 2013, habla de los indicadores negativos que ya en 2007, con su oponente socialista Rodríguez Zapatero en la presidencia, anunciaban la crisis; para incidir en tal hecho alude al incremento del déficit, pero no emplea, como hubiera sido lo oportuno, la cifra alcanzada por este, sino que se vale del adjetivo «brutal», cuya intención intensificadora oculta el dato real:

18. En el año 2007 había ya indicadores muy claros que señalaban la crisis y su dimensión, uno de ellos era especialmente potente, me refiero al brutal incremento del déficit de nuestra balanza de pagos por cuenta corriente, es decir, a nuestra brutal dependencia del exterior (Rajoy, 2013).

No obstante, una vez expresada la ponderación del incremento y conseguido el efecto mediante el vocablo, Rajoy, antes de cerrar el asunto, da un paso más al concretar, aunque sin llegar a la precisión requerida, con una cifra aproximada:

19. Con la consecuencia derivada de que la deuda de la economía española frente al exterior llegó a más del $90 \%$ de nuestro producto interior bruto. El gasto crecía sensiblemente por encima de la creación de riqueza [...] Para que se hagan una idea, señorías, en 2007, el incremento de la deuda externa rondó los 100.000 millones de euros (Rajoy, 2013).

¿Qué es más del 90\%? o ¿cuánto son los aproximadamente 100.000 millones de euros? No lo sabemos, pero sí tenemos un dato más próximo a la realidad que el indicado por el adjetivo brutal.

Igualmente sucede, aunque con un matiz distinto, en el enunciado que sigue: de los dos elementos vagos, "atenuar» y «aumento importante», solo se va a responder a uno, al segundo, pero no al primero:

20. Gracias a una utilización responsable de los nuevos instrumentos legales, tanto por parte de las empresas como de los trabajadores, se ha logrado atenuar la destrucción de empleo en un momento de grave recesión económica. También se aprecia un aumento importante, aunque gradual, de algunas formas de contrato potenciadas por la reforma laboral; destaca especialmente la evolución de los contratos en formación (Rajoy, 2013).

Su respuesta, a su vez, es esta:

21. Desde la entrada en vigor de la reforma se han firmado más de 55.000 contratos, lo que supone el mayor registro de los últimos cinco años. Además, ha crecido esta modalidad de contratación entre los trabajadores con niveles de cualificación más bajos y se han firmado ya 73.000 contratos de la nueva modalidad de apoyo a los emprendedores, de los cuales un $52 \%$ benefician a menores de treinta años (Rajoy, 2013).

\section{CONCLUSIONES}

Hemos intentado ver las dos caras del lenguaje vago para detenernos en una de ellas: la negativa, su cara perversa, la cual pretendimos ubicar como un mecanismo más dentro de las muy diferentes formas de manipulación; de estas, hemos propuesto determinados grupos de mecanismos y acciones que conducen al enmascaramiento lingüístico. La cara perversa del lenguaje vago tiene un sema diferenciador que es el que nos permite descubrir 
su función manipuladora: su intencionalidad; es esta la que le hace atentar contra alguno de los principios de Grice. Por ello, frente a la acepción general y amplia de vaguedad, nos hemos centrado en esta parcial manifestación, intencionada y negativa, que, como hemos propuesto, encuentra en un lenguaje como el político, de confrontación permanente, su natural acomodo. Junto a la función más conocida de la vaguedad, hemos encontrado una segunda mediante la cual el orador pretende crear expectativas en el auditorio; si bien, más adelante, una vez cumplidos sus objetivos, tales términos vagos son reemplazados por indicadores precisos.

A lo largo del artículo, aportamos enunciados pertenecientes a discursos de políticos españoles, especialmente de Rajoy, líder del Partido Popular, faltos de la determinación de unos límites designativos precisos; son fragmentos en los que el político intentará decir sin decir, de ocultar aquello que no ve que sea conveniente su difusión; todo cual, conseguido mediante el empleo del lenguaje vago, no es sino una manera de manipular al interlocutor.

\section{BIBLIOGRAFÍA}

ALKHATNAI, Mubarak (2017): «Vague Language and Its Social Role", Theory and Practice in Language Studies, 7/2, 122-127.

ALston, William (1964): Philosophy of language, Englewood Cliffs (NI), Prentice-Hall.

BARRANCO Flores, Nuria (2017): «El eufemismo léxico del discurso político y sus efectos cognitivos", Logos, 27/1, 15-30.

BAVELAS, Janet y otros (1990): Equivocal Communication, Newbury Park, Sage.

BoLívAR, Adriana (2014): «Si la burguesía volviera a ganar, Venezuela se volvería a hundir: la hipoteticalidad como estrategia en el discurso político», Revista de Filología de la Universidad de La Laguna, 32, 45-62.

BROWN, Gillian and George YULE (1983): Discourse Analysis, Cambridge, Cambridge University Press.

BuLL, Peter y Kate MAYER (1988): «Interruptions in political interviews: a study of Margaret Thatcher and Neil Kinnock», Journal of Language of Social Psychology 7, 35-45.

Bull, Peter y Kate MAYER (1993): «How Not To Answer Questions In Political Interviews", Political Psychology, 14/4, 651-666.

CAMERON, Deborah (1996): «The Language Gender Interface; Challenging Co-optation», en Bergvall, Victoria, Janet Bing and Alice Freed, eds., Rethinking Language and Gender, Londres, Longman, 31-53.

ChANNELL, Joanna. (1994). Vague language. Oxford, Oxford University Press.

CHOI, Hyangmi, Peter Bull y James D. ReEd (2016): "Audience Responses and the Context of Political Speeches», Journal of Social and Political Psychology, 4/2, 601-622.
CÓRdoba RodríGuez, María (2015): «El eufemismo político llevado al extremo: el caso Bárcenas», Círculo de Lingüística Aplicada a la Comunicación, 64, 127-146.

CRESPO-FERNÁNDEZ, Eliecer (2016): «Eufemismo y política: un estudio comparativo del discurso político local británico y español», Pragmalingüística, 24, 8-29.

CUTTING, Joan (2007). Vague Language Explored, Berlin, Springer.

CutTING, Joan (2015): «Dingsbums und so: Beliefs about German vague language», Journal of Pragmatics, 85, 108-121.

ERLICH, Frances y Giovanna CAIMI (2007): «Interacción argumentativa y falacias en el debate: perspectiva pragmadialéctica», Oralia, 10, 135-160.

FELdMAN, Ofer (2016): «Televised Political interviews: A Paradigm for Analysis», Asian Journal for Public Opinion Research, 3/2, 6382.

Feldman, Ofer, Ken Kinoshita y Peter Bull (2017): "Failures in Leadership», Journal of Language and Politics, 16/2, 285-312.

Feldman, Ofer, Ken Kinoshita y Peter Bull (2015): «Culture or Communicative Conflict? The Analysis of Equivocation in Broadcast Japanese Political Interviews», Journal of Language and Social Psychology 34/1, 65-89.

García Platero, Juan Manuel y María Auxiliadora Castillo Carballo (2013): «Lexicogénesis, eufemismos, y disfemismos en las tertulias políticas televisivas», en Fuentes, Catalina, coord., (Des)cortesía para el espectáculo: estudios de pragmática variacionista, Madrid, Arco/Libros, 197-210. 
GRASSO, Marina (2014): «Aspectos informativos del lenguaje vago», Lenguas Modernas, 43, 27-44.

GUTIÉRREZ MORALES, Irma Mariana, (2012): «Falacias en los discursos de los candidatos presidenciales en México (2012)», Revista Latinoamericana de Estudios del Discurso, 12/2, 11-32.

HeRnándeZ Flores, Nieves y María Elena GómeZ SÁNCHEZ (2014): "Actividades de imagen en la comunicación mediática de medidas políticas contra la crisis: el copago sanitario», Revista de Filología de la Universidad de La Laguna, 32, 125-144.

KEMPSON, Ruth (1977): Semantic theory, Cambridge, Cambridge University Press.

LIN, Liang. (2013). «Vague Language and Interpersonal Communication: An Analysis of Adolescent Intercultural», IJSCL, 1/2, 69-80.

LÓPEZ MARTíneZ, María Isabel (2003): «Aproximación al estudio de la redundancia en la comunicación política», en Ramón Almela y otros (cords.), Homenaje al prof. Estanislao Ramón Trives, Murcia, Universidad, 451-466

MÁRQUEZ GUERRERO, María (2012): «La paradoja de la atenuación en el discurso político. Su funcionalidad argumentativa en las interpelaciones de parlamentarias y parlamentarios andaluces", Discurso y sociedad, 6/1, 187-215.

Méndez García de PAREDES, Elena (2014): «La parodia informativa como frivolización del discurso político», Círculo de Lingüística Aplicada a la Comunicación, 59, 61- 91.

NICASIO AlVAREZ, Israel (2017): «Las deformaciones de la verdad en política: Del discurso al sometimiento", Revista de Filosofía de la Universidad de Costa Rica, 56, número 144, 233-238.

PeIRCE, Charles Sanders (1902): Vague (in logic), en James Baldwin (ed.), Dictionary of Philosophy and Psychology, Vol. II, Londres, Macmillan and Co.

PEIRES, Mary Louise (1997): «Come about Five-ish: Vagueness in Language», Southern African Journal of Applied Language Studies, 5, 56-69.

PIQUER I VIDAL, Adolf y Javier VELLón (2014): «Política económica y comunicación. Estrategias informativas en las ruedas de prensa del Ejecutivo español»,_Cultura, Lenguaje y Representación, 13, 245- 265.

TANNEN, Deborah (1986): That's not What I Meant!, Londres: William Morrow.

TANNEN, Deborah (1990): You Just Don't Understand: Women and Men in Conversation. Nueva ork, William Morrow.

TANNEN, Deborah (1993), ed., Gender and Conversational Interaction, Nueva York, OuP.

ZHANG, QUIAO (1998): «Fuzziness, vagueness, generality y ambiguity», Journal of Pragmatics, 29, 13-31. 